Please do not remove this page

RMIT

UNIVERSITY

\title{
Continuing professional development for RMIT International University Vietnam library staff: Adding value through an international partnership: A case study
}




\title{
Continuing Professional Development for RMIT International University Vietnam Library Staff: Adding Value through an International Partnership
}

\author{
JULIA LEONG \\ University Library, RMIT University, julia.leong@rmit.edu.au \\ LOC HUU NGUYEN \\ Beanland Library, RMIT International University Vietnam, loc.nguyen@rmit.edu.vn
}

\begin{abstract}
The aim of this study was to explore the effectiveness of blended learning - the fusion of face-to-face and online learning experiences - to implement an effective and culturally sensitive program of professional development in an Australian university working in a developing country. It sought insight into pertinent pedagogical approaches for staff development across multiple locations including across national boundaries. The project demonstrates how learners can develop new capabilities and approaches by building on existing skills and knowledge as they interact in communities of practice. The immediate purpose was to design and deliver a continuing professional education program to meet the needs of librarians working at RMIT International University Vietnam in the context of the demands of the academic community and in the light of the challenge library staff experienced in seeking to meet explicit and tacit expectations. The project ran from late January to mid December 2010. The research questions were: 'Is blended learning effective as an approach to continuing professional development when working across cultures in a multinational organization?' and 'What contribution do face-to-face and online components make to learning outcomes?' The methodology used was an action learning approach. A 2009 consultant's report into the RMIT Vietnam Library established professional developmental needs which were further detailed in February 2010 by the project leader from RMIT University, Melbourne using a skills audit. Workshops in Vietnam, visits to Melbourne by several Vietnam staff members, and an online forum were then delivered. Reflective practice and ongoing input from staff were utilized to form a feedback loop to modify the project timing and approaches as needed. Evaluation included participant feedback on workshops, tracking changes in Library services, a customer survey, a project-end survey of participants' behavioral changes against learning topics as self-reported, and discussion with participants. The authors were actively involved in the project: Julia Leong as project leader and Loc Nguyen as project champion at the Saigon South Campus. Blended learning was found to be effective in meeting continuing professional developmental needs and in promoting positive changes in library service provision. Online discussions were effective for extending existing knowledge, gaining practical hints, and examining attitudes. Face-toface workshops and visits were more effective for learning new material in a systematic way. It is recommended that consideration be given to applying the blended learning model used in this project to continuing professional developmental work in similar contexts.
\end{abstract}

Keywords: Continuing professional development, Staff development, Academic libraries, Australia, Vietnam

\section{INTRODUCTION}

International partnerships present organizations with new challenges, but also with great opportunities. Continuing professional education is an area which can be significantly enhanced by harnessing the know-how of staff in other organizations and by engaging in interactive learning activities. This article reports on a successful program of continuing professional development involving RMIT University library staff in Vietnam and Australia.

In 2010, a year-long project engaged library staff in Melbourne, Australia and Vietnam in a series of interactions and learning activities. RMIT International University Vietnam (RMIT Vietnam) has two campuses: the Hanoi Campus and the Saigon South Campus in Ho Chi Minh City. In Australia, the university is based in Melbourne and has libraries at six sites. While the project had benefits for the libraries in both Australia and Vietnam, the primary focus was to assist the Vietnam library staff to meet their customers' service delivery expectations of a modern academic library. This article focuses on the need for professional development, the effectiveness of the implemented blended learning approach, and the outcomes of the project in Vietnam. It also includes consideration of the factors which are thought to have contributed to the positive outcomes. 


\begin{abstract}
Methodology
An action learning approach was taken to this project which delivered a blend of face-to-face and online learning experiences. A consultant's report into the RMIT Vietnam Library identified a need for professional development. An initial visit by the project leader from RMIT University, Melbourne, comprising workshops, a skills audit and discussion, increased understanding of the needs. After this initial stage, the activities and timelines were developed. Ongoing input from staff and reflective practice formed a feedback loop to modify timing and approaches as needed. Project components were workshops in Vietnam conducted by Melbourne staff, visits by several Vietnam staff to RMIT University in Melbourne, an online community of practice, and informal coaching. Interaction between library staff in Melbourne and Vietnam was a key element. The authors filled the roles of project leader and project champion at the Saigon South Campus and were in a position to influence outcomes. Evaluation included participant feedback on workshops, tracking changes in Library services, a customer survey, a project-end survey of participants' behavioral changes against learning topics as self-reported, and discussion with participants.
\end{abstract}

\title{
THE NEED: THE SITUATION IN VIETNAM
}

\section{RMIT Library Customers}

Customers of RMIT Vietnam Library are a diverse international community of students, lecturers and staff. Starting with just 30 students in 2001, RMIT Vietnam reached a student body of more than 5,000 in 2009. About $10 \%$ of students come from countries other than Vietnam, such as Australia, Britain, the USA, France, Russia, Singapore, Korea, and Taiwan (RMIT University Vietnam, 2011). The growth in student numbers continues, as does the appointment of new teaching staff. Since academics also come from all over the world, they have brought to RMIT Vietnam a broad range of knowledge, teaching experience and approaches. As one of the key departments whose resources and services strongly contribute to the quality of teaching and learning, the library must understand the varied information needs of the groups it serves. Library staff must also appreciate the particularity of individual needs.

Students are enrolled in undergraduate, postgraduate and English courses at the two campuses of RMIT Vietnam. Studying with international standard curricula, all students are required not only to be present in the classrooms for lectures, but also to engage in academic activities such as producing assignments independently, working on assignments in groups, preparing and delivering presentations, examining case-studies, and participating in industrial projects. To be successful in these activities, students need to become information literate; that is to be able to clarify their own needs and create search strategies to find answers for their assignment questions. Hence, librarians are not only expected to be information professionals who can give answers to reference questions, but also educators who can design and facilitate information literacy classes for students. To offer good customer service, it is also very important to provide a friendly and comfortable atmosphere where students can easily express their problems and ask for help. This is especially needed when students are experiencing stress such as in response to assignment deadlines or looming examinations.

Most RMIT Vietnam teaching staff members are from English speaking countries, some are from Asian countries, and a small number are from Vietnam. All are required to hold an internationally recognized Masters degree or higher qualifications together with in-depth professional knowledge and teaching experience. Apart from teaching, many academics also pursue higher study and are engaged in research. All of these activities require them to explore a wide range of high quality and specialized information sources. As many lecturers have good information research skills, they only occasionally request help to locate information. Interaction between academics and library staff does occur regularly in relation to the acquisition of books and other items for the collection. These items are subject to thorough customs checks in Vietnam and this can cause delays. Robinson (2007, p. 257) referred to clearances required to import books into Vietnam, noting that foreigners do not always realize the extent of the influence of politics and government in day to day business. At times, lecturers were frustrated by the slowness in acquiring library resources and library staff struggled to deal confidently and empathically with their reactions and questions. 


\section{RMIT Vietnam Library}

The primary function of RMIT Vietnam Library is to support the teaching, learning, research and other scholarly activities of academics, students and staff of the university. It can be considered a small academic library with a collection of over 30,000 titles of books and other learning materials. The library also provides access to a large number of online databases through RMIT University Library in Melbourne. As of 2009, services offered to library customers included circulation, reference and interlibrary loan. There were also orientation and library tours held for new students, as well as general training sessions on how to use the library catalog and online databases.

\section{Library Staff}

At the time of the project, the total number of library staff working in the Saigon and Hanoi campuses was 17. Among them, the library manager graduated from the Masters program of the Graduate School of Library and Information Science of Simmons College in Boston, Massachusetts, USA, another librarian also held a Masters degree, and 12 others had a Bachelor degree in library and information science programs offered by top universities in Vietnam. They were a group of well qualified, mostly young, staff who were confident, enthusiastic, friendly and strongly committed to developing the range and quality of library services and resources.

Library staff were very comfortable working with students as age barriers were minimal. However, as many staff members were recent graduates, they lacked sufficient experience in dealing with customers who are dissatisfied and in handling difficult reference questions. For several reasons, most staff members were under-confident, and therefore sometimes awkward, in approaching and building up working relationships with the academics. One of the reasons was that formal intercultural training courses, which are necessary for people working in a multicultural workplace such as RMIT Vietnam, had not been established for Vietnamese staff. At times cultural differences would lead to misunderstandings and undermine harmony and respect.

Continued improvements in the library and its collection over time were resulting in improved customer satisfaction ratings in the annual customer survey, but results were still below a desirable level. At the invitation of RMIT Vietnam, a senior member of RMIT University Library visited Vietnam in 2009 to assess how well the learning support needs of the students and academic staff were being met. Her report identified developmental needs in the areas of customer focus, reference, liaison with academics, and support for information literacy development. As lecturers and students held high expectations of good customer service, training for library staff needed to cover issues such as dealing with 'difficult' customers, answering advanced queries, and handling challenging situations. In the area of information literacy, library staff needed to develop more advanced skills in designing and developing information literacy lessons, presenting classes, preparing training materials, and promoting information literacy classes. There was also a need to better understand how to apply a customer focus to planning, how to manage expectations, and how to build understanding of the potential value the library could offer in support of teaching and learning.

\section{THE LEARNING PROJECT}

As evidenced in the previous section, there was a clear need for continuing professional development (CPD) in several areas. The importance of CPD for library and information professionals is widely affirmed (IFLA, 2010; Maesaroh \& Genoni, 2010), however in the context of RMIT Vietnam, training and development were not readily available locally to match the need. Despite this, RMIT Vietnam did have significant opportunities in its international connection with RMIT University and internal funding was provided jointly in 2010 to address the CPD need.

The project leader visited the Saigon South Campus in early 2010 to clarify developmental needs through use of a self-rating competency audit and discussion with library staff. She also delivered introductory workshops on customer service and marketing. A blended learning approach was chosen to address the situation and was delivered throughout 2010 with evaluation in December 2010. It involved face-to-face workshops, visits to Melbourne by several staff, online discussions, and informal coaching. While face-to-face workshops are a traditional 
approach which allowed experts to impart new content, it was important not to be prescriptive, but rather to allow time and opportunity for participants to see how ideas would fit with their existing understandings and apply in their own cultural and organizational contexts. The intent to apply a constructivist approach came from recognition on the part of the project leader that: she was not familiar with the Vietnam context; authority and responsibility lay with the RMIT Vietnam Library Manager; and people are more likely to apply new approaches if they determine them for themselves. There was a desire to avoid one-off workshops and impractical instructions from an uninformed outsider with the likely failure that would result (Robinson, 2007, p. 258; Sward \& Leong, 2010).

\section{Workshops}

Face-to-face workshops were crucial to meet the cultural learning preferences of the Vietnamese staff and provided an opportunity to build mutual trust and respect. In most cases, PowerPoints or outlines of the session were provided to participants one or two weeks in advance to improve understanding as English proficiency varied. In the workshops, discussion and work in small groups were used regularly to promote active learning and to ensure material was understood. Four librarians from Melbourne were involved in delivering workshops over different visits. The earlier visit to Saigon South, which covered customer service and services marketing, was condensed for a May visit to Hanoi. In May, a Melbourne library manager also led workshops at both Vietnam campuses on the topics of dealing with difficult queries and the reference interview. The focus in October was on information literacy, with leadership from the manager of the Business Liaison Team and a reference librarian, both from Melbourne. Additionally the project leader ran workshops on EndNote and engineering resources for interested Saigon South staff and work planning training for all staff.

Participation in the workshops was higher than in other project components with almost all staff in attendance. In Saigon South, each workshop was run twice to avoid service disruption. In the smaller Hanoi Library, the enquiry desk was staffed by a member of another area who would call a librarian out of the workshop for help if needed. Evaluation forms provided very positive feedback on the value of workshops, although it was clear that some found it challenging to interact in English and needed leaders to speak slowly and clearly.

\section{Visits to Melbourne}

The Vietnam Library Manager visited RMIT University in Melbourne for two weeks in April. A schedule was developed to meet her expressed needs and interests and she benefited greatly from time spent with a variety of colleagues, gaining ideas which were quickly put into practice (A. T. T. Hoang, personal communication, December 10, 2010). In September, the Information Services Coordinators from both campuses and a reference librarian enjoyed a visit to Melbourne where they focused on reference and information literacy work and management issues. The visits were a good opportunity to build understanding of one Western model of service provision and to gain insight into how liaison librarians work with academics. When reflecting on their experiences later, the Information Services Coordinators spoke of the value of gaining an understanding of the liaison librarian role, observing the friendly attitudes of staff toward students, and noting managers' proactive approach to problem solving (T. B. Leu \& V. T. T. Pham, personal communication, December 10, 2010). The visits also provided a valuable opportunity for Vietnamese staff to interact with Australian staff and to form professional bonds which will support ongoing networking.

\section{Online Forum}

In addition to face-to-face interactions, an online site was developed to provide resources and facilitate development of a community of practice. The online site was titled Equip: Equipping Librarians to Provide Effective Learning Support and was generally referred to as the Equip forum or simply Equip. It was developed with the Drupal Content Management System and used a combination of core Drupal modules, contributed modules and modules developed for the project. It was integrated with the Novell Directory Services of the university which allows staff to utilize their usual work login and password. The Equip site was used to reinforce and extend workshop material and contained resources and a space for discussion. Online discussions provided the opportunity for a larger number of Melbourne staff to be involved and to benefit from the project. The major forum topics were customer service (May), reference work 
(June) and information literacy (November). Days and times were pre-arranged to hold real-time discussions. Although posts could be made at any time, the majority of participants utilized the site only at designated times and these were usually exciting. Participation rates in Vietnam were variable with a number of staff gaining great benefit and others less involved. Fourteen Vietnam staff completed a project-end evaluation with nine reporting that they had posted on the Equip forum. One read posts actively, but did not post, three did not participate in the forum and one did not answer this question. Total staff at the end of the project numbered 12 at Saigon South and five in Hanoi. The level of involvement generally reflected the staff members' duties with acquisitions/cataloging staff less active in the forum where discussion was centered on information services issues. Part-timers were also less able to participate than full-time staff.

When a sizeable number of participants were online together, the fast pace of the posts did make it challenging for some staff to process the incoming ideas in time to post comments of their own, but they were able to look back over the material later as it was well categorized on the site. While 12 of the 14 Vietnam respondents to the final survey affirmed that they would recommend the mix of learning approaches used in the project, there was some feedback that the Equip discussions were potentially a little intimidating, and use of chat, such as Skype, with a smaller number of participants, may have been preferable, or a useful addition.

\section{Action Learning}

After each phase of the project, reflection and feedback were used to adjust the future phases to suit needs. Content adjustments were the easiest to make. Dates for visits had to fit in with the academic calendars and hence were relatively inflexible. An example of an adjustment was the abandonment of a plan to teach selection processes through the forum. Instead time was provided during the September visit to Melbourne for staff to develop greater skills in this area, equipping them to on-train their colleagues at a later date. This change reflected our observation that the forum worked well for exchange of ideas, but less well for teaching and learning new skills.

\section{OUTCOMES}

The project had very positive and substantial impact. Outcomes were measured in a number of ways including: participants' evaluations of workshops; reports from those who visited Melbourne; a project-end online survey of participants; observation and reflection; conversations with library staff and others; and a Library (Customer) Survey. A blended learning approach to continuing professional development of library staff was found to be highly effective in our context. In the survey at the conclusion of the project in December 2010, in answer to the statement, "For me, the project has been worthwhile", the average of all participants' ratings was 4.7 out of a possible best of 5, with 5 meaning Strongly Agree and 4 meaning Agree. For Information Services staff only the average was 4.8.

\section{Increased Networking between Library Staff}

With the establishment of the Equip online forum, librarians in Melbourne, Saigon and Hanoi had a very significant place for sharing their ideas and examples of best practice. After the launch in May, a variety of issues were raised for discussion and there were also a number of specific queries and answers. As library staff members on all campuses were involved in contributing and gaining ideas, the forum became an effective place for everyone to build up new connections, strengthen mutual understanding and improve practice.

One of the notable features of the forum was the categorization of discussion topics. There were four main groups of topics consisting of 45 small topics that drew hundreds of posts from participants. Since the number of small topics rose tremendously, individuals could choose just the ones related to their interests. Topic categorization was valuable as it enabled librarians to identify other colleagues who shared the same interests. This allowed for more productive interactions on- and off-line. Over time participants gained more understanding of each other, and hence became more confident in raising questions and expressing ideas. In addition, several means of communication beside the online forum were deployed for further conversations between Melbourne and Vietnam staff. Some Information Services staff in Vietnam started to approach their Australian colleagues by emails, chat reference, Skype and 
even Facebook to gain additional input on specialized issues such as dealing with 'difficult' customers, collection development for new academic programs, library services marketing, and social media applications in promoting library services. Also, social network accounts such as Twitter, Linkedln, and Delicious were exchanged as a convenient way to keep in touch. Although the project has now concluded, the online forum is still available for use and a number of professional buddy pairs have been established between librarians in Vietnam and Melbourne to continue networking.

In addition to increased interactions between Australian and Vietnamese staff, the utilization of the forum also inspired more in-depth collaboration between librarians in the Saigon South and Hanoi campuses. There has been increased cooperation in a number of practical areas among colleagues on the two Vietnam campuses. For example, immediately after the October series of workshops in Vietnam specializing in information literacy, a remarkable number of further conversations were held to prepare for collaborative work on designing and delivering library training classes for students. One of the methods used to connect was the internal phone network of RMIT Vietnam as it is suitable for long synchronous conversations between campuses. The practical outcome was that Information Services staff in both campuses successfully discussed and agreed on the design of the initial lesson plan for general online databases training workshops which can be modified to apply to course-tailored workshops. An interesting tool, introduced by Australian librarians, was Yammer. Library staff in Vietnam found Yammer especially beneficial when they created discussion groups to share ideas with each other over a four week period at the same time as they were delivering information literacy workshops. This allowed them to keep improving the quality of their training materials as well as the effectiveness of their teaching methods.

New Working Relationships between the Vietnam Library and Other Areas of the University

One of the areas of high interest to the Vietnam library staff was how best to build supportive effective and respectful relationships between librarians and academics. This was discussed in all the components of the project and progress has been good. The project served as a circuit breaker for some negative perceptions which had been held about the library and resulted in increased and improved interaction with other organizational units in Vietnam. More productive working relationships were established with academics and with other support areas working to build students' information literacy competency.

Prior to the project, information literacy training was predominantly offered by the Learning Skills Unit which is responsible for teaching essential study skills. The library offered general training workshops on using the library catalog and searching online databases, but attendance was low. A small number of subject specific information literacy classes were presented by an educational technologist in response to requests from lecturers. Having been apprised of the situation, the project leader arranged a meeting of all support units involved in information literacy training to avoid duplication in effort. Open discussion between the stakeholders clarified and agreed boundaries and resulted in the transfer of some responsibilities to the library. In preparing new lesson plans and training materials since then, the library has benefited greatly from advice offered by staff members of the Learning Skills Unit and Educational Technology. These units have also been supportive in referring lecturers to the library when there is a need for tailored information literacy classes.

After attending workshops focused on information literacy in October, Vietnamese librarians were more active and confident in approaching the academics to offer workshops relevant to the course needs of their students. By emails and direct conversations, new contacts with several academics were created. The new connections were strengthened when lecturers observed that students who participated in the workshops showed noticeable improvement in the quality of the information and sources used and cited in their assignments. All lecturers who arranged for librarians to present tailored workshops cheerfully expressed their satisfaction and agreed to continue working together in the following semesters.

\section{Changed Library Practices and Improved Services}

There have been a number of changes in the way the Vietnam library seeks to support learning and teaching as a result of the project. Primarily these relate to: building staff expertise in discipline areas taught; approaches to liaison with academics; information literacy activities; and promotion of library services. One of the challenges faced by staff in Vietnam is how to build 
adequate expertise across the increasing number of disciplines taught. When the Vietnam Library Manager visited Melbourne, she observed the liaison librarian model in operation and then introduced a contextualized approach in Saigon South by allocating subject responsibilities to staff. This promotes some specialization and provides the opportunity for staff to build up expertise and support each other, such as by offering database training for their allocated area in the future.

There has been significant progress in the area of information literary training and this was discussed in the previous section. The library in the Saigon South Campus now regularly offers classes tailored to students' course needs. Also, newly recruited librarians in Hanoi Library were greatly helped by timely workshops on this area as tailored workshops were being requested at the time of the Melbourne librarian visit. Additional changes have been the introduction of a common template for lesson planning and the inclusion of student learning activities to improve understanding of class content.

In discussing customer service at the start of the project, a services marketing approach underpinned topics such as library planning and working with students and academics. This resonated well with Vietnam staff and an increased marketing focus has been evident. Use of social media for marketing library services was already being actively explored and since then discussions have taken place to seek to integrate promotion opportunities into the university student portal. An idea raised by staff in discussions, which came to fruition quickly, was a Book Fair organized by the Vietnam Library on July 22-23, 2010 at which three book distributors displayed thousands of titles and offered a discount to staff and students wishing to purchase items.

\section{Growth in Confidence and Improved Individual Practice}

RMIT Vietnam is distinctive in offering a Western style of education in the English language within Vietnam. There is an intention that RMIT Vietnam operates in close alignment to RMIT University providing an equivalent educational experience and the library is expected to operate as a modern academic library. Library staff members are all Vietnamese and academics and senior executives are predominantly Westerners. Incoming academics are provided with cultural awareness briefings; however, at the time of this project, the equivalent training was not available to Vietnamese staff. This situation, in addition to restrictions and delays on the importation of books, made it difficult for the library to meet the expectations of the academic community fully. Melbourne librarians offered explicit information on the likely assumptions and expectations of the academic community. They also took advantage of occasional opportunities to build support for the library from academics and other staff they met. Library staff members who visited Melbourne were able to observe cultural differences and library practices first hand, and the workshop in Vietnam on dealing with difficult queries was helpful. In a feedback survey conducted by the Vietnam Library Manager one to two weeks after the workshop, participants reported their knowledge on this topic as having improved from an average of 3.6 up to 4.4 out a possible best of 5 . Library marketing activities have increased to promote better understanding of the services and of the growth in the library collection. Anecdotal evidence is strong that relationships with library customers are now more positive and harmonious and Information Services staff report increased interaction with academic staff. Additionally, there has been an increase in numbers of staff delivering workshops and those involved report growing confidence in this work.

As part of the final participants' survey, library staff were asked to rate their knowledge, attitudes and activities before, and after, the project on a 1-5 scale for 17 items which related to the learning topics. The results were pleasing. The best possible score was 5 and across all items and all Vietnam survey respondents the average moved from a baseline of 3.6 up to 4.3, showing an overall improvement of $17 \%$.

\section{Customer Opinions}

A December 2010 survey provided clear evidence of a positive trend from the customers' viewpoint. Customers were asked to rate library performance on a number of items using a 1 to 4 scale (1 Not good, 2 Fair, 3 Good, 4 Excellent). There were four questions about library staff which were highly relevant as a measure of the effectiveness of the learning project when 2010 responses were compared with 2009 data. They were 'Knowledge in answering your questions', 'Friendliness', 'Helpfulness', and 'Availability'. In 2010, Hanoi Campus students' opinions 
showed improvements of $5.91 \%, 4.75 \%, 3.34 \%$, and $0.4 \%$ respectively. Saigon Campus students' ratings improved by $3.41 \%, 1 \%, 7.36 \%$, and $6.04 \%$ respectively. Average ratings by academic and other staff were higher than those of students.

\section{Drivers of Success}

There are a number of factors which contributed to the success of this project. These factors were not specifically studied, but included:

- the enthusiasm of staff to be involved and openness to learn from each other;

- the availability of an enthusiastic project leader, detailed planning, and ongoing interaction to keep the project on track;

- the support of senior university and library staff;

- funding provided by the university;

- the work of project champions in Saigon South, Hanoi, and some Melbourne campuses;

- the expertise, availability, and willingness of several Melbourne librarians to prepare and present workshops in Vietnam;

- the willingness of a number of Melbourne librarians to facilitate online discussion on allocated days;

- careful scheduling which took account of the university calendars to schedule interaction in the less busy periods;

- the expert support from the RMIT University Melbourne educational technology group in developing an online site;

- cooperation, support and advice from other departments in Vietnam such as the Learning Skills Unit and Educational Technology;

- attention to communication and promoting involvement; and

- time zones which are close enough for synchronous online discussion to be possible.

With any successful project, a number of factors underpin the positive outcomes. Being strong at one factor, while weak at another, will lessen the quality of the outcomes. In this project we were fortunate that the needed drivers of success were present. Perhaps the list above can be summarized as having the required resources, organizational skill, and motivation and openness to change.

Resources include financial backing, time to participate, and talent. The project could not have gone ahead without the financial backing of RMIT University and RMIT Vietnam. The Vice President (Academic) in Vietnam provided high level support as did the University Librarian in Melbourne. With their support, the project leader applied for funding through the RMIT University Learning and Teaching Innovations Program. This was granted with matching funding from RMIT Vietnam which has finances separate from the University in Melbourne. In addition to finance, a key resource was provision of time to complete the project. The financial grant included provision for three months of staff replacement time for the project leader to enable her to develop resources, coordinate the project, liaise with the Vietnam Library, and lead workshops. It is estimated that the University Library in Melbourne provided another three months of staff time in total for the project leader and three other librarians who delivered workshops in Vietnam. In addition, libraries in both countries provided time within working hours for staff to participate in learning activities. Another major success factor was the availability of a pool of talented and committed trainers. RMIT University Library is a large academic library with many talented managers and librarians who are well equipped to offer excellent training.

Organizational skill is a major driver of success in project management. The organization and coordination of this project rested largely with the project leader who has a strong record as a project leader, expertise in staff development, and relevant experience in library management. The Library Manager in Vietnam worked with the project leader to coordinate content and delivery and to promote staff interest and involvement. In this she was ably assisted by the Information Services Coordinators in Saigon South and Hanoi.

Motivation and openness to change can make or break a professional developmental project. The Vietnam Library staff members are to be complemented on their enthusiasm in this area. The reasons for their positive attitudes were not explored, but may include: the leadership of the Library Manager who had been educated overseas; the natural exuberance of youth as 
many of the staff are in the early stages of their career; the excitement generated by an opportunity to engage with international colleagues; and the deliberate focus of an early workshop on a known area of concern, or use of a learning 'hook' to heighten learning motivation.

\section{CONCLUSION}

Blended learning was found to be a highly effective approach for continuing professional development of library staff in our multinational university. Each of the major components of the project - face-to-face workshops, overseas visits, and online forums - was highly rated by those involved. The inclusion of face-to-face contact is vital to establish effective working relationships based on trust and respect. Such relationships break down barriers to learning by reducing any sense of intimidation or fear of speaking up with opinions or questions. Multiple times and points of contact are important to build motivation and to provide time for people to absorb, consolidate and apply new ideas. The online forum was most suitable for extending existing knowledge, gaining practical hints, and examining attitudes. The face-to-face workshops and visits were more effective for learning new material in a systematic way.

This action research involved one case study of continuing professional development of library staff in two countries. As each situation is unique, the results may vary in other contexts where personalities, resources, challenges and learning needs are different. Nevertheless, the mix of learning approaches used in this project resulted in clear gains in staff competence and confidence and in improved customer satisfaction and thus the model is worthy of consideration as a strategy for application in other contexts.

\section{REFERENCES}

IFLA. (2010). About the Continuing Professional Development and Workplace Learning Section. Retrieved 10 January, 2011, from http://www.ifla.org/en/cpdwl.

Maesaroh, I., \& Genoni, P. (2010). An investigation of the continuing professional development practices of Indonesian academic libraries. Library Management, 34(8/9), 621-634. RMIT University Vietnam. (2011). Programs. Retrieved 12 January, 2011, from http://www.rmit.edu.vn/663_ENG_HTML.htm.

Robinson, M. (2007). Consulting across cultures: Librarians and project management in Vietnam. Library Management, 28(4-5), 252-261.

Sward, B., \& Leong, J. (2010). The Vietnam connection. [news]. inCite, 31(12), 15. 